OPEN ACCESS

Edited by:

Petr Pavek,

Charles University, Czechia

Reviewed by:

Zhihao Liu,

University of Illinois at Chicago,

United States

Cesare Indiveri,

Università della Calabria, Italy

*Correspondence:

Lanxiang Wu

Ixwu2008@126.com

Specialty section:

This article was submitted to Drug Metabolism and Transport,

a section of the journal

Frontiers in Pharmacology

Received: 04 September 2018

Accepted: 29 October 2018

Published: 20 November 2018

Citation:

Zhao H, Huang Y, Shi J, Dai Y, Wu L and Zhou H (2018) ABCC10 Plays a Significant Role in the Transport of Gefitinib and Contributes to Acquired

Resistance to Gefitinib in NSCLC

Front. Pharmacol. 9:1312

doi: 10.3389/fphar.2018.01312

\section{ABCC10 Plays a Significant Role in the Transport of Gefitinib and Contributes to Acquired Resistance to Gefitinib in NSCLC}

\author{
Hongbo Zhao ${ }^{1}$, Yutang Huang ${ }^{2}$, Jingjing Shi ${ }^{2}, \mathrm{Yi} \mathrm{Dai}^{2}$, Lanxiang $\mathrm{Wu}^{2 *}$ and \\ Honghao Zhou ${ }^{2,3}$
}

${ }^{1}$ Shanghai Key Laboratory of Female Reproductive Endocrine Related Diseases, Obstetrics and Gynecology Hospital, Fudan University, Shanghai, China, ${ }^{2}$ Institute of Life Sciences, Chongqing Medical University, Chongqing, China,

${ }^{3}$ Pharmacogenetics Research Institute, Institute of Clinical Pharmacology, Central South University, Changsha, China

Gefitinib, an epidermal growth factor receptor (EGFR) tyrosine kinase inhibitor (EGFR-TKI), is used clinically as first-line therapy in patients with advanced non-small cell lung cancer (NSCLC) with EGFR activating mutations, but the inevitable development of acquired resistance limits its efficacy. In up to $30-40 \%$ of NSCLC cases, the mechanism underlying acquired resistance remains unknown. ATP-binding cassette (ABC) transporters are a family of membrane proteins that can significantly influence the bioavailability of numerous drugs, and have confirmed to play an essential role in multidrug resistance (MDR) in cancer chemotherapy. However, their role in acquired resistance to gefitnib in NSCLC has not been well studied. Here, through RNA sequencing (RNA-Seq) technology we assessed the differentially expressed $A B C$ transporters in gefitinib-sensitive (PC9 and H292) and gefitinib-resistant (PC9/GR and H292/GR) NSCLC cells, with ABCC10 identified as a transporter of interest. Both ABCC10 mRNA and protein were significantly increased in acquired gefitinib-resistant NSCLC cells, independent of EGFR mutation status. In vitro transport assay showed that $A B C C 10$ could actively efflux gefitinib, with an efflux ratio (ER) of 7.8. Further results from in vitro cell line models and in vivo xenograft models showed that overexpression of ABCC10 led to a reduction in gefitinib sensitivity through decreasing the intracellular gefitinib accumulation. Our data suggest that $\mathrm{ABCC} 10$ has an important role in acquired resistance to gefitinib in NSCLC, which can serve as a novel predictive marker and a potential therapeutic target in gefitinib treatment.

Keywords: $A B C$ transporter, $A B C C 10$, gefitinib, acquired resistance, non-small cell lung cancer

\section{INTRODUCTION}

Lung cancer is by far the leading cause of cancer-related deaths in both men and women (Ridge et al., 2013). Non-small cell lung cancer (NSCLC) represents approximately $85 \%$ of all lung cancer case, with 5 -year survival rates of only $16 \%$ (Tas et al., 2013). In $40-80 \%$ of NSCLCs, the epidermal growth factor receptor (EGFR) has been found to be overexpressed, which is believed 
to contribute to the NSCLC cell proliferation, differentiation, and survival (Ennis et al., 1991; Salomon et al., 1995; Jutten and Rouschop, 2014). In 2015, gefitinib, one of the first-generation EGFR tyrosine kinase inhibitors (EGFR-TKIs), was approved by the United States Food and Drug Administration (USFDA) as a first-line treatment for metastatic NSCLC patients with activating EGFR mutations, resulting a longer progression-free survival (PFS) compared to standard cytotoxic chemotherapy (Gridelli et al., 2011; Douillard et al., 2014). Besides, previous studies also support that a considerable proportion of NSCLC patients harboring wild-type EGFR still achieve clinical benefit from gefitinib treatment (Zhou and Zhou, 2015; Shepherd, 2016).

Although gefitinib has a favorable clinical response, almost all patients will eventually develop acquired resistance after 1014 months, which finally leads to treatment failure (Gandara et al., 2014). To date, many mechanisms of acquired resistance to gefitinib have been defined in around $60-70 \%$ of cases, which can be classified into three categories: secondary EGFR mutations, phenotypic transformation, and activation of alternative pathways (Morgillo et al., 2016). However, the mechanisms in about $30-40 \%$ of cases still remain unknown.

ATP-binding cassette $(\mathrm{ABC})$ transporters are a family of membrane proteins that pump out of the cells a variety of endogenous and exogenous substrates in an ATP-dependent manner (Schinkel and Jonker, 2003). Nearly 40 years of research indicates that $\mathrm{ABC}$-mediated multidrug efflux is one of the most important mechanisms of multidrug resistance (MDR), a major obstacle in the clinical treatment of various cancers. Due to the strong correlation between $\mathrm{ABC}$ transporters and MDR, a number of $\mathrm{ABC}$ inhibitors have been developed and tested in clinical trials. Unfortunately, the majority of trials did not confirm clinical benefit. There are multiple reasons for these negative results, but one of the main reason is the insufficient knowledge of the interactions between $\mathrm{ABC}$ transporters and chemotherapy drugs (Jaramillo et al., 2018; Mohammad et al., 2018; Robey et al., 2018). Owing to considerable overlap among the substrate profiles of the various $\mathrm{ABC}$ transporters, multiple transporters may be involved in the efflux of a specific chemotherapy agent. Therefore, it is critical that all known ABC transporters be studied within a single study, rather than focusing on individuals (Tamaki et al., 2011). In the case of gefitinib, only its interactions with ATP binding cassette transporter G2 (ABCG2), ATP binding cassette transporter B1 (ABCB1), and ATP binding cassette transporter $\mathrm{C} 1$ (ABCC1) have been examined previously. ABCG2 has been shown to be a high affinity gefitinib transporter, at least at submicromolar concentrations, and likely play an important role in acquired resistance to gefitinib (Leggas et al., 2006; Usuda et al., 2007; Azzariti et al., 2010; Chen et al., 2011; Hegedüs et al., 2012; Zhu et al., 2015). While $A B C B 1$ and $A B C C 1$ exhibit much lower affinities toward gefitinib (Ozvegy-Laczka et al., 2004; Beretta et al., 2017). However, no investigations into the interaction between other $\mathrm{ABC}$ transporters and gefitinib have been conducted so far.

In the present study, we mapped the expression of 48 human $\mathrm{ABC}$ transporters in the gefitinib-sensitive and -resistant NSCLC cell lines using RNA sequencing technology, and found that ABCC10 (ATP binding cassette subfamily C member 10), also known as MDR protein 7 (MRP7), was significantly upregulated in cells with acquired resistance to gefitinib. Results from in vitro cell culture models and in vivo xenograft models showed that ABCC10 could actively pump gefitinib out of cells, and its overexpression led to a reduction in gefitinib sensitivity through decreasing the intracellular gefitinib accumulation.

$\mathrm{ABCC} 10$ is an important member of $\mathrm{ABC}$ transporter superfamily. Accumulating research has revealed that ABCC10 actively transports a broad range of cytotoxic chemotherpy agents, such as taxanes, vinca alkaloids, antifolates, cisplatin, daunorubicine, etoposide, irinotecan, epothilone $\mathrm{B}$, as well as nucleoside analogs, leading to the occurrence of MDR (Wu et al., 2016; Dabrowska and Sirotnak, 2017). Additionally, ABCC10 may interact with some EGFR-TKIs. A recent study has shown that lapatinib and erlotinib reverse ABCC10-mediated MDR through inhibition of the drug efflux function (Kuang et al., 2010). Here, our data suggest that $\mathrm{ABCC} 10$ has an important role in acquired resistance to gefitinib in NSCLC, which can serve as a novel predictive marker and a potential therapeutic target in gefitinib treatment.

\section{MATERIALS AND METHODS}

\section{Cell Lines and Cultures}

The EGFR-mutant PC9 (exon 19 deletion E746-A750) and EGFR wild-type H292 NSCLC cell lines, as well as Lewis lung carcinoma-porcine kidney epithelial cell line (LLC-PK1) were purchased from the Cellular Institute of Chinese Academy of Science. NSCLC cell lines were cultured with RPMI 1640 supplemented with $10 \%$ fetal bovine serum (FBS), and LLC-PK1 cells were maintained in complete Dulbecco's modified Eagle's medium (DMEM) supplemented with 10\% FBS. All the cell lines were cultured in a $5 \% \mathrm{CO}_{2}$ incubator at $37^{\circ} \mathrm{C}$.

To establish acquired gefitinib-resistant cell lines PC9/GR and H292/GR, PC9 and H292 cells were continuously exposed to increasing dosages of gefitinib for $\sim 12$ months. Established resistant cell lines were maintained by culture in a medium containing $2 \mu \mathrm{mol} / \mathrm{L}$ gefitinib. To eliminate the effects of gefitinib, the resistant cells were cultured in a drug-free medium for at least 2 weeks before all experiments.

\section{Establishment of Stable Cell Lines}

The human $A B C C 10$ or $A B C G 2$ gene was inserted into the EcoRI and XbaI sites of pcDNA3.1(+) (Invitrogen, Carlsbad, CA) to make expression vectors, pcDNA3.1(+)/ABCC10 or pcDNA3.1(+)/ABCG2.

To establish ABCC10-overexpressing NSCLC cells, gefitinib-sensitive PC9 and $\mathrm{H} 292$ cells were transfected with pcDNA3.1(+)/ABCC10 or empty vector using Lipofectamine ${ }^{\mathrm{TM}}$ 2000 (Invitrogen, Carlsbad, CA, USA). To establish NSCLC cells with ABCC10 knockdown, ABCC10 shRNA plasmid (shABCC10, Santa Cruz Biotechnology, sc-62641-SH) or control plasmid (shMock, Santa Cruz Biotechnology, sc-108060) was introduced into gefitinib-resistant NSCLC cells PC9/GR and H292/GR. Single colonies were identified in culture medium containing G418 (2 mg/mL) and subcultured for further analysis. 
To establish the stably transfected LLC-PK1 cells expressing $\mathrm{ABCC} 10$ or $\mathrm{ABCG} 2$, pcDNA3.1(+)/ABCC10, or pcDNA3.1 $(+) / A B C G 2$ was transfected into LLC-PK1 cells, and stable transfected clones were selected as described above. Expression of ABCC10/ABCG2 was confirmed by quantitative real-time PCR and western blot analysis as described below.

\section{Cell Viability Assay}

Cell viability was measured using the CellTiter96 Aqueous One Solution Cell Proliferation Assay (MTS) (Promega, Madison, WI, United States). In brief, cells were plated in 96-well plates at the density of $2 \times 10^{4}$ cells per well. After $24 \mathrm{~h}$ incubation, cells were treated with various concentrations of gefitinib $(0.1-$ $10 \mu \mathrm{mol} / \mathrm{L}$ ) for $72 \mathrm{~h}$. Then, the $20 \mu \mathrm{L}$ of MTS reagent was added to each well and the plates were incubated for an additional $2 \mathrm{~h}$. The absorbance was read at $490 \mathrm{~nm}$ using a microplate reader (SynergyTMH4, BioTek, United States). Cell viability was calculated as a percentage relative to vehicle-treated control. the $\mathrm{IC}_{50}$ value was calculated based on the non-linear regression fit method by Graphpad Prism 4.0 software (San Diego, CA).

\section{Cell Apoptosis Assay}

For apoptosis assay by flow cytometry, cells were seeded in 6-well plates at a concentration of $2 \times 10^{5}$ cells per well, and treated with $1 \mu \mathrm{mol} / \mathrm{L}$ gefitinib for $72 \mathrm{~h}$. Cells were then digested with trpsin and washed with PBS three times, incubated with $5 \mu \mathrm{L}$ of FITC-conjugated Annexin-V and $5 \mu \mathrm{L}$ of propidium iodide (PI) (Thermo Fisher Scientific, MA, United States) for $15 \mathrm{~min}$ in a dark place at room temperature. The stained cells were detected using the BD Accuri C6 flow cytometer (BD Biosciences, CA, United States). At least 10,000 cells were analyzed for each group.

\section{RNA Isolation and RNA Sequencing (RNA-Seq) Analysis}

Total RNA was isolated from $1 \times 10^{7}$ cells using the mirVana ${ }^{\mathrm{TM}}$ miRNA ISOlation Kit (Ambion, Austin, TX, United States) following the manufacturer's instruction. $1 \mu \mathrm{g}$ of total RNA was used to prepare standard RNA-seq libraries (TruSeq Stranded Total RNA kit with Ribo-Zero Gold, Illumina). RNA integrity was validated for size using the Agilent 2100 Bioanalyzer (Agilent Technologies, CA, United States) and sequenced by a $2 \times 125$ bp paired-end sequencing module on an Illumina HiSeq 2500 (Oebiotech, Shanghai, China). The criteria for differential gene expression included a fold change $\geq 2$ between compared groups and statistical significance at $P<0.05$.

\section{Reverse Transcription and Quantitative Real-Time PCR}

Total RNA was isolated from the cells using TRIzol reagent (Invitrogen, Carlsbad, CA, United States), and the first strand cDNA was synthesized using the Revert Aid TM H Minus First Strand cDNA Synthesis Kit (TaKaRa Bio, Shiga, Japan) according to the manufacturer's instruction. Quantitative real-time PCR (qRT-PCR) was performed using SYBR Premix Ex Taq II (Takara Bio, Shiga, Japan) according to the manufacturer's instructions. The sequences of the $A B C C 10$ primers were 5 -CGGGTTAAG CTTGTGACAGAGC-3' (forward) and $5^{\prime}$-AACACCTTGGTG
GCAGTGAGCT-3' (reverse). PCR programs were carried out as follows: $95^{\circ} \mathrm{C}$ for $30 \mathrm{~s}$, followed by 40 cycles of $95^{\circ} \mathrm{C}$ for $5 \mathrm{sec}, 60^{\circ} \mathrm{C}$ for $30 \mathrm{~s}$. $\beta$-actin served as an internal control. Relative quantification of $A B C C 10$ was analyzed using the $2^{-\Delta \Delta C \mathrm{t}}$ method as a ratio relative to the $\beta$-actin expression level in each sample (Livak and Schmittgen, 2001).

\section{Protein Isolation and Western Blot Analysis}

Crude membrane fraction from cells was isolated as described previously (Revalde et al., 2015). Total protein was extracted using RIPA buffer (Beyotime, Shanghai, China), with PMSF (Sigma, Missouri, United States). The Pierce BCA Protein Assay Kit (Thermo Fisher Scientific, Waltham, United States) was used to determine the protein concentration. The protein extracts were separated by $10 \%$ sodium dodecyl sulfate-polyacdene gel electrophoresis and transferred onto polyvinylidene difluoride membranes (Bio-Rad, Hercules, CA, United States). The membranes were incubated with anti-ABCC10, anti-ABCG2, anti- $\beta$-actin, and anti-Na ${ }^{+} / \mathrm{K}^{+}$-ATPase primary antibodies (Abcam, Cambridge, United Kingdom) at $4^{\circ} \mathrm{C}$ overnight, probed with horseradish peroxidase-conjugated secondary antibodies (Abcam, Cambridge, United kingdom), and signals were detected by ECL ${ }^{\mathrm{TM}}$ Prime (GE Healthcare, Buckinghamshire, United Kingdom) and a LAS-3000 imager (Fujifilm, Tokyo, Japan). $\beta$-actin and $\mathrm{Na}^{+} / \mathrm{K}^{+}$-ATPase expression levels were used to normalize the total and membrane expression levels of ABCC10.

\section{Measurement of Intracellular Gefitinib Accumulation Assay}

Concentrations of gefitinib accumulated in cells were determined using a validated Liquid chromatography tandem mass spectrometry (LC-MS/MS) method. The cells were cultured in the 6-well plates at a density of $1 \times 10^{6}$ per well and were grown to $85 \%$ confluence. Then, the cells were treated with varying concentration of gefitinib with or without 2.5 $\mu \mathrm{mol} / \mathrm{L}$ cepharanthine at $37^{\circ} \mathrm{C}$ for $4 \mathrm{~h}$, harvested and washed in cold PBS. Gefitinib was extracted from cells with $200 \mu \mathrm{L}$ of a methanol/water mixture $(50 / 50, \mathrm{v} / \mathrm{v})$, cell extracts were centrifuged $\left(4^{\circ} \mathrm{C}, 12,000 \mathrm{rpm} / \mathrm{min}, 10 \mathrm{~min}\right)$ and collected. Samples were prepared by adding $20 \mu \mathrm{L}$ of internal standard solution $(100 \mathrm{ng} / \mathrm{mL}$, erlotinib) to $180 \mu \mathrm{L}$ of the cell lysates. Cell proteins were quantified using the BCA Protein Assay kit (Thermo Scientific, Rockford, IL, United States). LCMS/MS analysis was performed on an Agilent 1290 series liquid chromatography system (Agilent Technologies, Palo Alto, CA, United States) and an Agilent 6470 triple-quadruple mass spectrometer (Agilent Technologies, Santa Clara, CA, United States). An Agilent ZORBAX Eclipse Plus C18 column $(1.8 \mu \mathrm{m}, 3.0 \mathrm{~mm} \times 50 \mathrm{~mm})$ and a mobile phase [water (containing $0.1 \%$ formic acid) and methanol $(30: 70, \mathrm{v}: \mathrm{v})]$ at a flow rate of $3 \mathrm{~mL} / \mathrm{min}$ were applied. The ion transitions monitored were as follows: $\mathrm{m} / \mathrm{z} 447.1\left([\mathrm{M}+\mathrm{H}]^{+}\right)$to 128.4 $\left([\mathrm{M}+\mathrm{H}]^{+}\right)$for gefitinib, and $\mathrm{m} / \mathrm{z} 394.2\left([\mathrm{M}+\mathrm{H}]^{+}\right)$to 336.1 $\left([\mathrm{M}+\mathrm{H}]^{+}\right)$for erlotinib. The running time of each sample was $3 \mathrm{~min}$. The lower limit of quantification for gefitinib was $1 \mathrm{ng} / \mathrm{mL}$. The calibration curves were linear over the rage $1-500 \mathrm{ng} / \mathrm{mL}$ 
with mean correlation coefficients of 0.9997 . The intra- and inter-day coefficients of variation were $<10 \%$.

\section{LLC-PK1 Monolayer Transport Assay}

Polarized LLC-PK1 cells were used in transport assay. Wildtype LLC-PK1 (LLC-WT) cells, human ABCC10 or ABCG2 gene transfected LLC-PK1 (LLC-ABCC10 or LLC-ABCG2) cells were seeded on the permeable polycarbonate Transwell ${ }^{\circledR}$ cell culture inserts ( $24 \mathrm{~mm}$ diameter, $0.4 \mu \mathrm{m}$ pore size; Costar, MA, United States) at a density of $2 \times 10^{6}$ per well for $72 \mathrm{~h}$. Before the start of transport assay, cells were washed with PBS and preincubated with Opti-MEM (Invitrogen, Carlsbad, $\mathrm{CA}$, United States) for $2 \mathrm{~h}$, then the experiment was stated by replacing the medium on either the apical or the basal side of the cell layer with fresh DMEM containing 10\% fetal calf serum and $10 \mathrm{nmol} / \mathrm{L}\left[{ }^{3} \mathrm{H}\right]$-estrone-3-sulfate, $100 \mathrm{nmol} / \mathrm{L}\left[{ }^{3} \mathrm{H}\right]$-paclitaxel, or $100 \mathrm{nmol} / \mathrm{L}\left[{ }^{3} \mathrm{H}\right]$-gefitinib with or without $2.5 \mu \mathrm{mol} / \mathrm{L}$ cepharanthine or $10 \mu \mathrm{mol} / \mathrm{L} \mathrm{Ko143}$. The cells were incubated at $37^{\circ} \mathrm{C}$ under $5 \% \mathrm{CO}_{2}$. After various time of incubation, $100 \mu \mathrm{L}$ of medium was taken from each compartment, and the radioactivity in each aliquot was measured in a liquid scintillation counter (LS6500; Beckman Coulter, Inc., Fullerton, CA, United States). Immediately after each of the experiments, fluorescein isothiocyanate (FITC)-conjugated dextran (MW $=40$ $\mathrm{kDa}$ ) was used to examine the integrity of the cell monolayer. Leakage of dextran had to remain $<1 \%$ of the total added radioactivity per hour. The apparent permeability $\left(P_{\text {app }}\right)$ was calculated by the following equation

$$
P_{\mathrm{app}}=\frac{d Q / d t}{A \times C_{0}}
$$

where $Q$ is the amount of radioactivity transported across the monolayer, $t$ is time, $d Q / d t$ is the rate of transport, $A$ is the effective surface area of the cell monolayer, and $C_{0}$ is the initial drug concentration. The efflux ratio (ER) was used as a meausre of ABCC10/ABCG2-mediated efflux, and calculated according to Equation 2:

$$
\mathrm{ER}=\frac{P_{\mathrm{app}} \mathrm{B} \rightarrow \mathrm{A}}{P_{\mathrm{app}} \mathrm{A} \rightarrow \mathrm{B}}
$$

where $P_{\text {app B } \rightarrow \text { A }}$ is the $P_{\text {app }}$ value measured in the basal to apical direction, and $P_{\text {app } \mathrm{A} \rightarrow \mathrm{B}}$ is the $P_{\text {app }}$ value measured in the apical to basal direction (Shaik et al., 2007).

\section{NSCLC Xenograft Mice Models}

The protocols of animal experiments were approved by the Animal Ethics and Experimental Committee of the Chongqing Medical University (Chongqing, China), and performed according to the National Institutes of Health Guide for the Care and Use of Laboratory Animals. Briefly, female Balb/c-nude mice (4-6 weeks, 16-20 g) were obtained from the Laboratory Animal Center of Chongqing Medical University (Chongqing, China), and randomized into four groups $(n=6)$. Mice subjected to subcutaneously injection with ABCC10-overexpressing PC9 cells (PC9-ABCC10), empty-vector transfected PC9 cells (PC9-EV), ABCC10-knockdown PC9/GR cells (PC9/GR-shABCC10), or
shMock-transfected PC9/GR cells (PC9/GR-shMock) $\left(5 \times 10^{6}\right.$ cells/mouse) in each right flank. When all tumors reached a mean volume of $50 \mathrm{~mm}^{3}$, the mice were treated with gefitinib (30 mg/kg/day) for 3 weeks by oral gavage. Tumor volume (TV) was calculated as formula: $\mathrm{TV}\left(\mathrm{mm}^{3}\right)=\left(\mathrm{L} \times \mathrm{W}^{2}\right) / 2(\mathrm{~L}$, lone diameter; $\mathrm{W}$, wide diameter). Body weights were recorded every 3 days. At the end of experiments, mice were sacrificed and the tumors were removed.

\section{Immunohistochemical Staining}

PC9 xenografts were collected, fixed in 4\% paraformaldehyde, embedded in paraffin. Slides from each group were deparaffinized in xylene, and incubated with anti-Ki-67 antibodies (Abcam, Cambridge, United kingdom). The primary antibody was detected with a biotinylated goat anti-rabbit IgG. Three slides per groups were read and scored for the number of Ki-67-positive cells using the Visiomorph Integrator image analysis system. The proliferating cells were estimated by the percentage of Ki-67 positive-stained cells in 10 randomly chosen high-powered fields for each section $(\times 400)$.

\section{Statistical Analysis}

Statistical analysis was performed using the SPSS 20.0 software (IBM SPSS, Armonk, NY, United States). Heat map was performed by Clustering (version 3.17.1). All values were expressed as mean \pm SEM. One-way ANOVA and subsequent post hoc Tukey's test were performed to analyze the differences between sets of data. Values of $P<0.05$ were considered statistically significant.

\section{RESULTS}

\section{Gene Expression Profile of ABC Transporters in Gefitinib-Sensitive and -Resistant NSCLC Cell Lines}

In order to explore a new mechanism of acquired resistance to gefitinib in NSCLC, the acquired gefitinib-resistant cell lines that were derived from the parental sensitive PC9 and H292 cells were established through continuous exposure of this drug, which were designated as PC9/GR and H292/GR. MTS proliferation assay was used to confirm the acquired resistance to gefitinib. The $\mathrm{IC}_{50}$ values for gefitinib was $0.15 \pm 0.03 \mu \mathrm{mol} / \mathrm{L}$ in PC9 cells, while PC9/GR cells showed about 32-fold resistance to gefitinib, with the $\mathrm{IC}_{50}$ value of $4.65 \pm 0.84 \mu \mathrm{mol} / \mathrm{L}$. Similarly, the $\mathrm{IC}_{50}$ was $1.01 \pm 0.22 \mu \mathrm{mol} / \mathrm{L}$ in $\mathrm{H} 292$ cells, and the H292/GR showed about 11-fold higher resistance to gefitinib, with the IC50 value of $10.90 \pm 1.8 \mu \mathrm{mol} / \mathrm{L}$ (Figure 1).

The gene expression profile of 48 human ABC transporters in gefitinib-resistant PC9/GR and H292/GR cells were examined using RNA-seq and compared with that of the parental cell lines. The changes in transcription level of 48 genes encoding $\mathrm{ABC}$ transporters in the gefitinib-sensitive and -resistant NSCLC cell lines were shown in Supplementary Tables 1, 2. The reliability and the reproducibility between assays were assessed by repeating the experiments three times for each cell line $(n=3)$. The transcripts with a greater than 2-fold change in expression and an adjusted two-sided $P<0.05$ were considered to have 

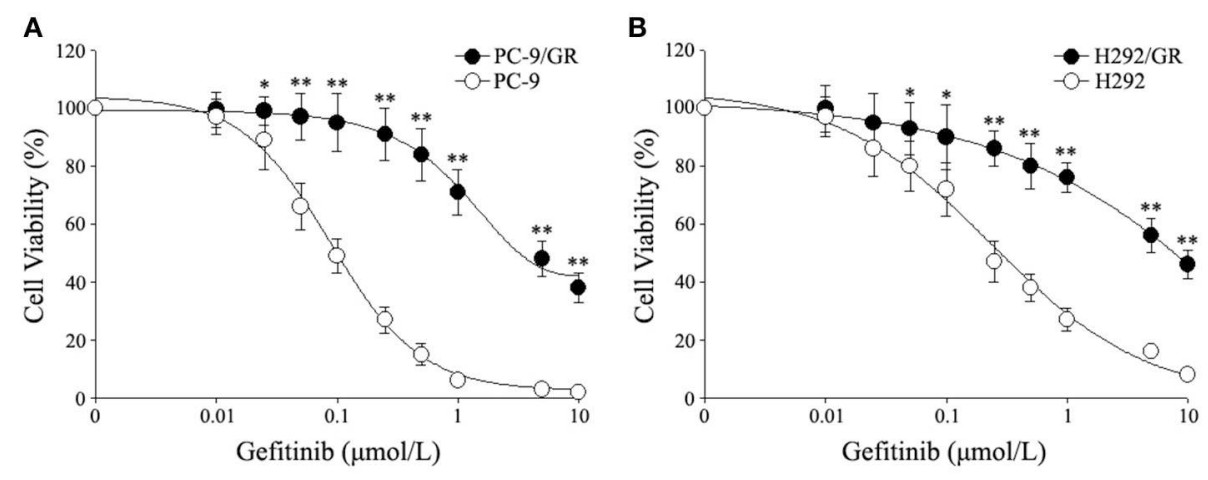

FIGURE 1 | Cytotoxic effects of gefitinib in acquired gefitinib-resistant NSCLC cell lines and their parental cells. PC9, PC9/GR (A) and H292, H292/GR (B) cells were cultured in 96-well plates and exposed to the indicated concentrations of gefitinib for $72 \mathrm{~h}$. The cell viability was analyzed using MTS assay as described in Meterials and Methods. The number of viable cells is expressed as a percentage of the value for untreated cells. ${ }^{\star} P<0.05$, ${ }^{\star \star} P<0.01$ compared to the parent-sensitive cell line.

significantly differential expression between two groups. Figure 2 shows the data for one representative experiment. Compared to their parental cells, four genes encoding $A B C A 1, A B C C 10$, $A B C G 2$, and $A B C E 1$ were significantly upregulated in PC9/GR cells, and five genes encoding $A B C C 4, A B C C 10, A B C D 3, A B C G 2$, and $A B C G 1$ were significantly upregulated in H292/GR cells. Therefore, the present results showed that except for $A B C G 2$, a transporter that is known to be responsible for the acquired resistance to gefitinib in NSCLC (Leggas et al., 2006; Usuda et al., 2007; Azzariti et al., 2010; Chen et al., 2011; Hegedüs et al., 2012; Zhu et al., 2015), ABCC10 was the only significant differential expressed transporter in both PC9/GR and H292/GR cells.

\section{ABCC10 Is Overexpressed in Gefitinib-Resistant NSCLC Cell Lines}

To verify the sequencing result, we quantitated the expression of ABCC10 mRNA in gefitinib-sensitive and -resistant NSCLC cell lines using qRT-PCR. Our results showed that the expression patterns observed in all cell lines were consistent with the RNAseq results. Compared to their parent-sensitive cell lines, ABCC10 mRNA levels were increased about 10.9-fold in PC9/GR cells, and 8.3-fold in H292/GR cells (Figure 3A). Then, we examined the levels of ABCC10 protein in the lysates prepared from total and membrane proteins isolated from these cell lines. Increased total and plasma membrane ABCC10 levels were observed in cells with acquired resistance to gefitinib. Moreover, compared to the whole cell lysates, the upregulation of ABCC10 level was more obvious in the plasma membrane of two resistant cells (Figure 3B).

\section{Influence of ABCC10 on Gefitinib Sensitivity in NSCLC Cells}

To study the influence of ABCC10 on gefitinib sensitivity in NSCLC cells, we modulated the expression level of ABCC10 either by overexpression in gefitinib-sensitive NSCLC cells, or knockdown in gefitinib-resistant NSCLC cells (Figure 4), then observed the cytotoxic effect of gefitinib. Our results showed that compared with empty-vector-transfected cells, ABCC10 overexpression significantly increased the cell survival rate after
$72 \mathrm{~h}$ of gefitinib exposure, the $\mathrm{IC}_{50}$ values were increased by 2.5-fold in PC9 cells, and 2.4-fold in H292 cells (Figures 5A,B). ABCC10 knockdown in gefitinib-resistant NSCLC cells caused about 38.5 and $34.1 \%$ reduction in $\mathrm{IC}_{50}$ values in PC9/GR and H292/GR cells, respectively (Figures 5C,D). In addition, after ABCC10 overexpression, gefitinib-induced apoptosis decreased from 27.7 to $15.3 \%$ in PC9 cells, and from 18.8 to $8.3 \%$ in H292 cells. Whereas ABCC10 knockdown led to increase rate of apoptosis from 6.6 to $10.4 \%$ in PC9/GR cells, and from 5.3 to $8.9 \%$ in H292/GR cells (Figure 6).

\section{Influence of ABCC10 on Intracellular Concentration of Gefitinib in NSCLC Cells}

The results above indicate that ABCC10 might play an important role in acquired resistance to gefitinib. Mechanistically, we detected the intracellular accumulation of gefitinib in NSCLC cells with different levels of ABCC10 expression. As shown in Figure 7, after ABCC10 overexpression, the intracellular gefitinib concentrations in gefitinib-sensitive PC9 and H292 cells were decreased by 25.3 and $23.7 \%$, respectively. While after ABCC10 knockdown, the gefitinib-resistant cells showed higher intracellular concentration of gefitinib, 1.5-fold and 1.4fold increases in PC9/GR and H292/GR cells, respectively. As expected, cepharanthine, an ABCC10 inhibitor (Zhou et al., 2009), could almost completely reverse the negative influence of ABCC10 on intracellular gefitinib accumulation (Figure 7).

\section{ABCC10-Mediated Gefitinib Transport in vitro}

As mentioned above, ABCC10 overexpression resulted in a decrease in the intracellular accumulation of gefitinib. Therefore, we evaluated whether gefitinib was a substrate of ABCC10 in vitro. As gefitinib is also a substrate of ABCG2, at least in the submicromolar concentration (Ozvegy-Laczka et al., 2004; Leggas et al., 2006; Azzariti et al., 2010; Hegedüs et al., 2012; Beretta et al., 2017), the ABCG2-mediated efflux of gefitinib was simultaneously observed in this study. Monolayers of wildtype LLC-PK1 (LLC-WT) cells, as well as its subclones transduced 
A

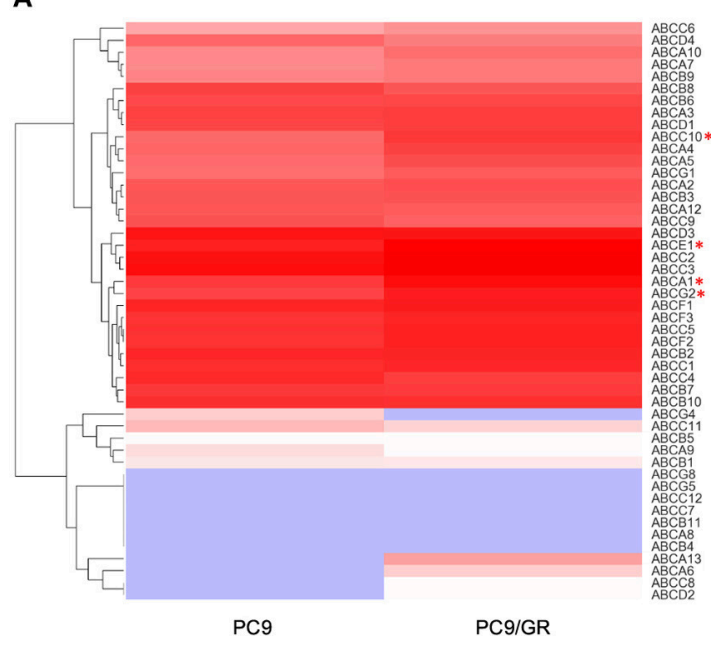

B

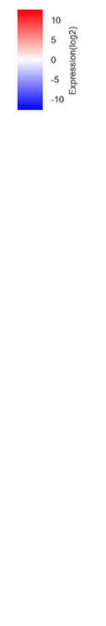

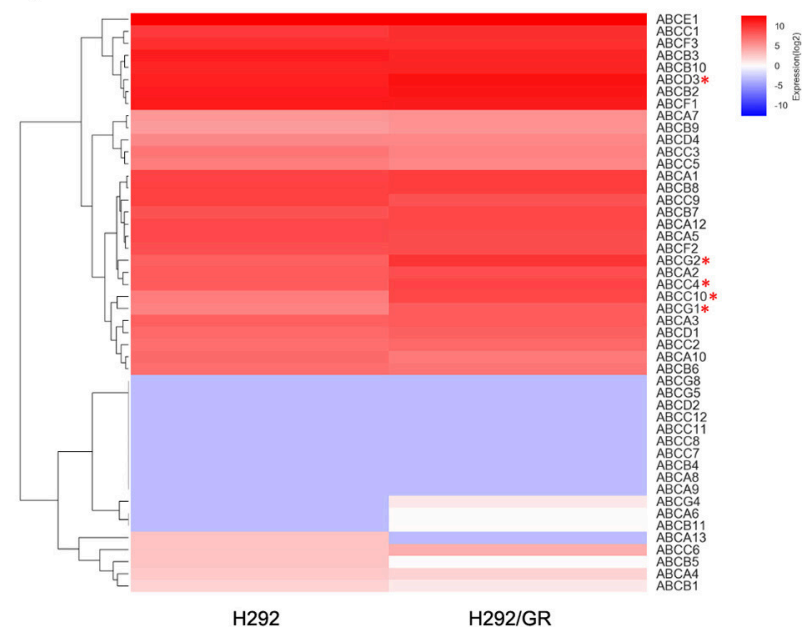

FIGURE 2 | Differentially expressed genes encoding ABC transporters between gefitinib-sensitive and -resistant cell lines. (A) Analysis of differentially expressed genes between PC9 and PC9/GR cell lines. (B) Analysis of differentially expressed genes between H292 and H292/GR cell lines. Expression intensities are displayed from blue (low expression) to red (high expression). ${ }^{*} P<0.05$ compared to the parent-sensitive cell line.

A

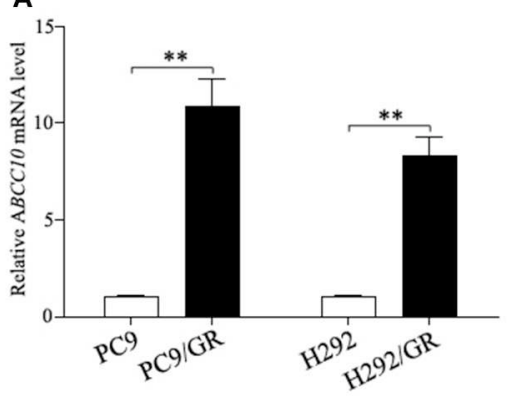

B

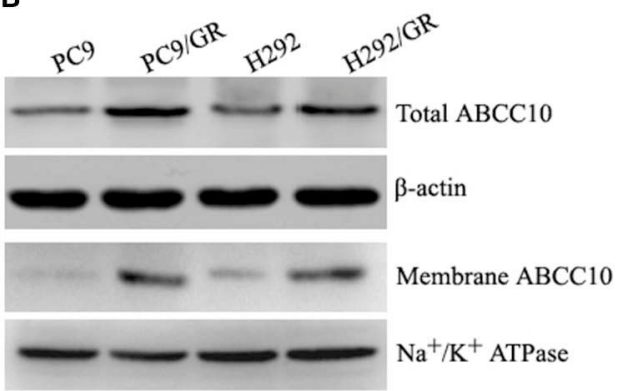

FIGURE 3 | ABCC10 expression in gefitinib-sensitive and -resistant NSCLC cell lines. (A) qRT-PCR analysis of ABCC10 mRNA levels in gefitinib-sensitive and -resistant NSCLC cell lines. (B) Western blot analysis of ABCC10 protein levels in gefitinib-sensitive and -resistant NSCLC cell lines. ${ }^{* \star} P<0.01$ compared to the parent-sensitive cell line.

with human $A B C C 10$ (LLC-ABCC10) or ABCG2 (LLC-ABCG2) were used in this study (Figures $\mathbf{8 A}, \mathbf{B}$ ). The polarized LLCABCC10 and LLC-ABCG2 cells predominantly exported $\left[{ }^{3} \mathrm{H}\right]$ paclitaxel and $\left[{ }^{3} \mathrm{H}\right]$-estrone-3-sulfate, two typical substrates for ABCC10 and ABCG2 (Hopper-Borge et al., 2004; Nakayama et al., 2011), from the basal to apical side, which indicates that both $\mathrm{ABCC} 10$ and ABCG2 localize mainly to the apical membrane (Figure 8C). As for gefitinib, there was no significant difference in its permeability in either direction in LLC-WT cells. However, the basal-to-apical permeability of gefitinib in the LLCABCC10 and LLC-ABCG2 cells were significantly greater than the apical-to-basal permeability, yielding ER values of 7.8 and 10.3 , respectively. The directional transport was abolished when the cells were treated with $2.5 \mu \mathrm{mol} / \mathrm{L}$ cepharanthine (ABCC10 inhibitor) or $10 \mu \mathrm{mol} / \mathrm{L} \mathrm{Ko} 143$ (ABCG2 inhibitor), indicating that, in addition to ABCG2, gefitinib is a good substrate of human ABCC10 (Figure 8D).

We further observed the ABCC10 and ABCG2-mediated gefitinib efflux activity in the presence of various substrate concentration using LLC-WT, LLC-ABCC10, and LLC-ABCG2 cells. After incubation with varying concentrations of gefitinib for $4 \mathrm{~h}$, the intracellular gefitinib accumulation was measured by LC-MS/MS assay. The results showed that LLC-ABCC10 and LLC-ABCG2 cells exhibited significantly lower intracellular accumulation of gefitinib at concentration of 1 and $10 \mu \mathrm{mol} / \mathrm{L}$ than the LLC-WT cells. However, at the higher concentrations of 20 and $50 \mu \mathrm{mol} / \mathrm{L}$, reduced cellular gefitinib accumulation was only observed in LLC-ABCC10 cells, not in LLC-ABCG2 cells, likely due to inhibition of ABCG2 activity at higher concentrations (Ozvegy-Laczka et al., 2004; Leggas et al., 2006; Figure 9).

\section{Influence of $A B C C 10$ on Gefitinib Sensitivity in NSCLC Xenograft Mice Models}

To further determine whether ABCC10 could reduce the efficacy of gefitinib in vivo, PC9 xenograft models were established in female nude mice. Four cell lines, PC9-ABCC10, PC9-EV, PC9/GR-shABCC10, and PC9/GR-shMock were injected 

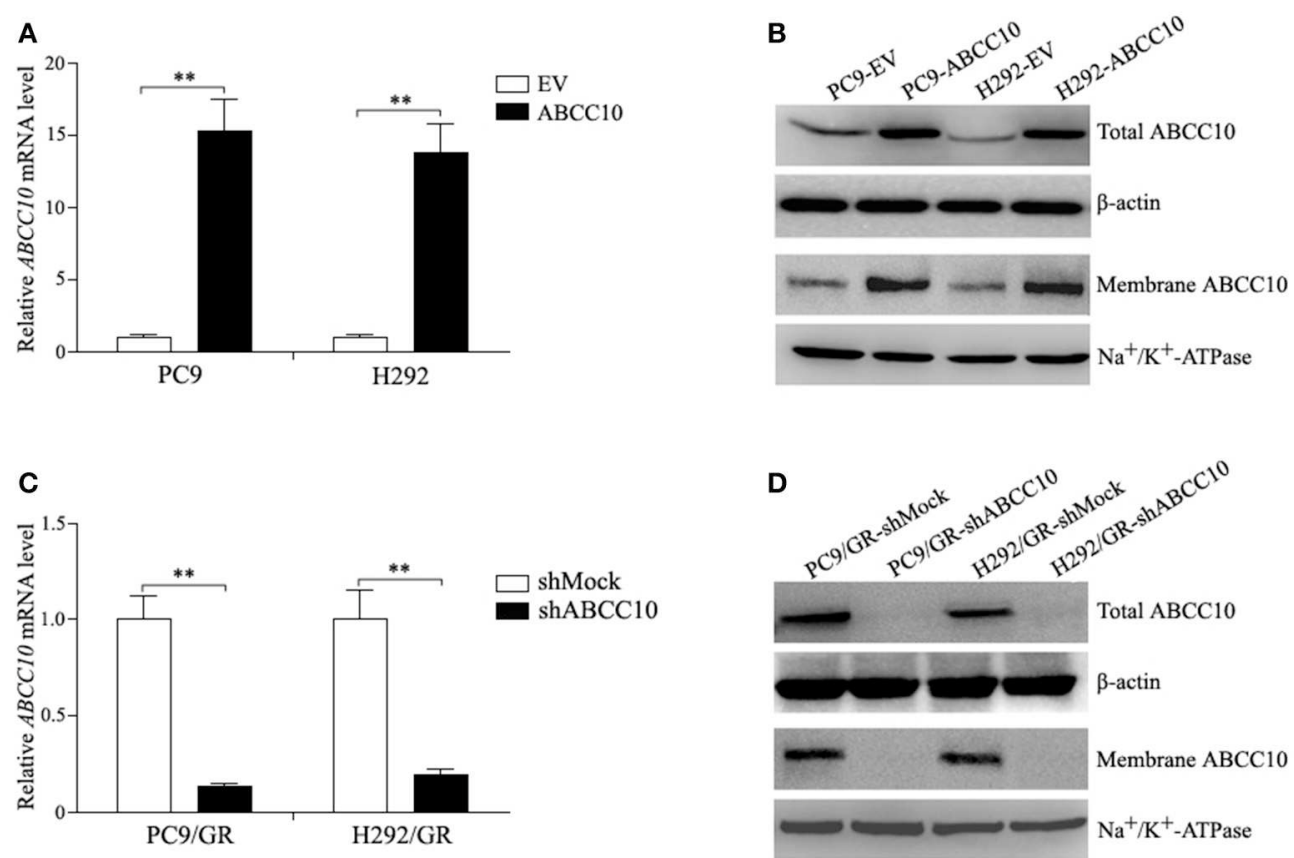

FIGURE 4 | ABCC10 expression in gefitinib-sensitive and -resistant NSCLC cells following ABCC10 overexpression and knockdown. (A,B) ABCC10 mRNA and protein levels in gefitinib-sensitive PC9 and H292 cells following ABCC10 overexpression. (C,D) ABCC10 mRNA and protein levels in gefitinib-resistant PC9/GR and H292/GR cells following ABCC10 knockdown. ${ }^{\star \star} P<0.01$ compared to the empty-vector-transfected cells (EV) or shMock-transfected cells (shMock).
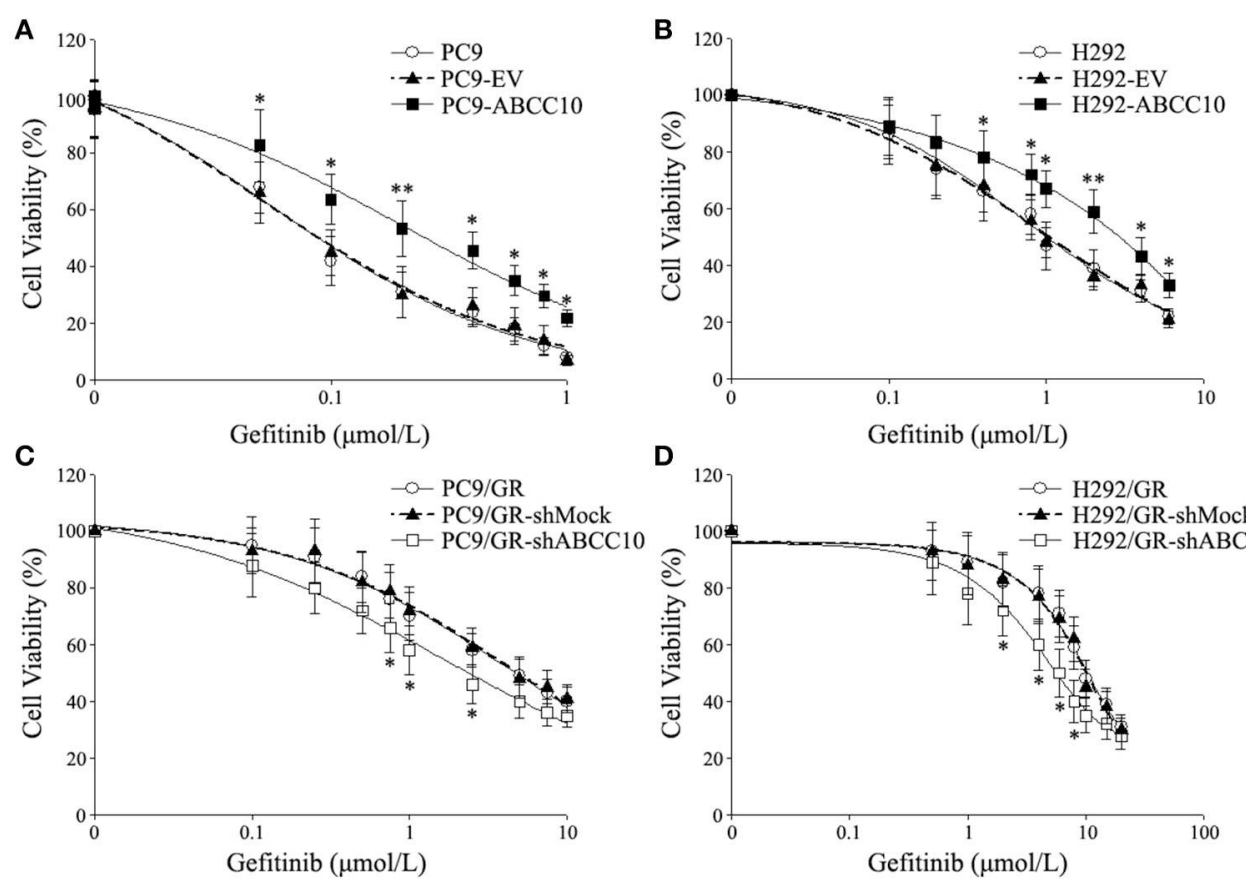

FIGURE 5 | Effect of ABCC10 on cell viability of gefitinib-sensitive and -resistant NSCLC cells after gefitinib exposure. (A,B) Influence of ABCC10 overexpression on cell viability of gefitinib-sensitive PC9 and H292 cells treated with various concentration of gefitinib for $72 \mathrm{~h}$. (C,D) Influence of ABCC10 knockdown on cell viability of gefitinib-resistant PC9/GR and H292/GR cells treated with various concentration of gefitinib for $72 \mathrm{~h}$. ${ }^{*} P<0.05,{ }^{\star \star} P<0.01$ compared to the empty-vector-transfected cells (EV) or shMock-transfected cells (shMock). 

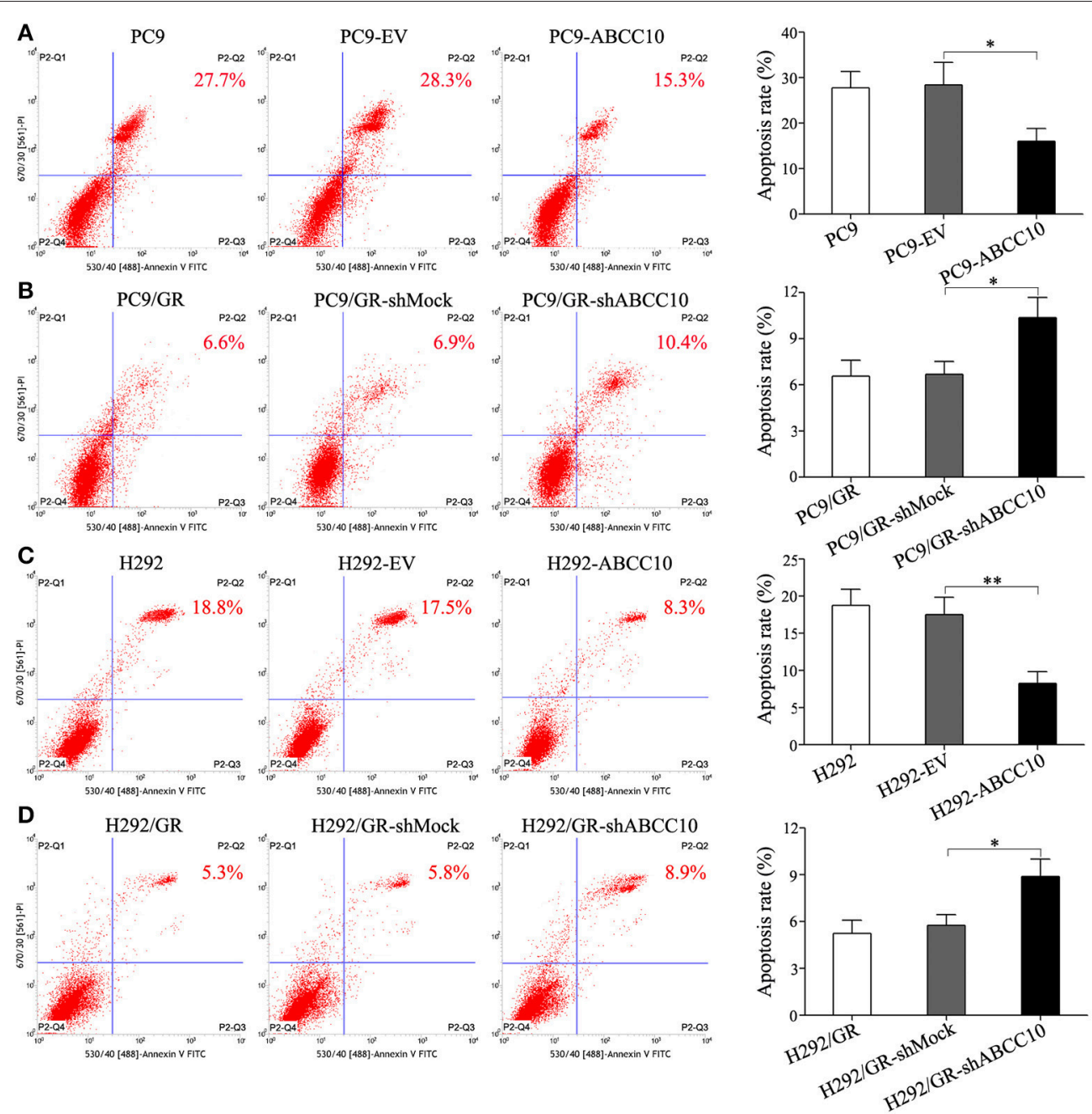

FIGURE 6 | Effect of ABCC10 on cell apoptosis of gefitinib-sensitive and -resistant NSCLC cells after gefitinib exposure. (A,C) Influence of ABCC10 overexpression on cell apoptosis of gefitinib-sensitive PC9 and H292 cells treated with $1 \mu \mathrm{mol} / \mathrm{L}$ gefitinib for $72 \mathrm{~h}$. (B,D) Influence of ABCC10 knockdown on cell apoptosis of gefitinib-resistant PC9/GR and H292/GR cells treated with $1 \mu \mathrm{mol} / \mathrm{L}$ gefitinib for $72 \mathrm{~h} .{ }^{\star} P<0.05$, ${ }^{\star \star} P<0.01$ compared to the empty-vector-transfected cells (EV) or shMock-transfected cells (shMock).

subcutaneously into mice, and the mice began receiving gefitinib treatment when tumor volumes reached $50 \mathrm{~mm}^{3}$. After the 3 -week treatment period, no significant alterations on average body weight were observed among groups (Figure 10A). Compared with PC9-EV group, the average TV and tumor weight showed 1.4 -fold $\left(231.4 \pm 94.5 \mathrm{~mm}^{3}\right.$ vs. $168.3 \pm 77.7$ $\left.\mathrm{mm}^{3}\right)$ and 1.3 -fold $(0.9 \pm 0.3 \mathrm{~g}$ vs. $0.7 \pm 0.2 \mathrm{~g})$ increases in PC9-ABCC10 group. Similarly, compared with PC9/GRshMock group, ABCC10 knockdown significantly decreased the average TV and tumor weight by $19 \%\left(365.8 \pm 96.5 \mathrm{~mm}^{3}\right.$ vs. $\left.452.1 \pm 86.3 \mathrm{~mm}^{3}\right)$ and $12 \%(1.5 \pm 0.4 \mathrm{~g}$ vs. $1.7 \pm 0.5 \mathrm{~g})$ in PC9/GR-shABCC10 group, respectively (Figures 10B,C). Additionally, we detected the expression of Ki-67, a wellknown proliferation marker in NSCLC samples (Tabata et al., 2014). After ABCC10 overexpression, the percentage of Ki-67-positive cells was significantly increased from $21.1 \%$ in PC9-EV group to $30.8 \%$ in PC9-ABCC10 group. While after ABCC10 knockdown, the percentage of Ki-67-positive cells was markedly decrease from 64.5\% in PC9/GR-shMock group to $53.4 \%$ in PC9/GR-shABCC10 group (Figure 10D). These results suggested that $\mathrm{ABCC} 10$ could reduce the sensitivity of NSCLC cells to gefitinib in vivo, and inhibition of ABCC10 expression could partially restore the sensitivity to gefitinib.

\section{DISCUSSION}

ABC transporters play an important role in the absorption, distribution, and elimination of a wide variety of drugs in clinical use, including anticancer chemotherapeutic agents. Numerous studies has confirmed that ABC transporters play an essential role in the development of MDR to chemotherapy. These results lead to the development of three generations of $\mathrm{ABC}$ 


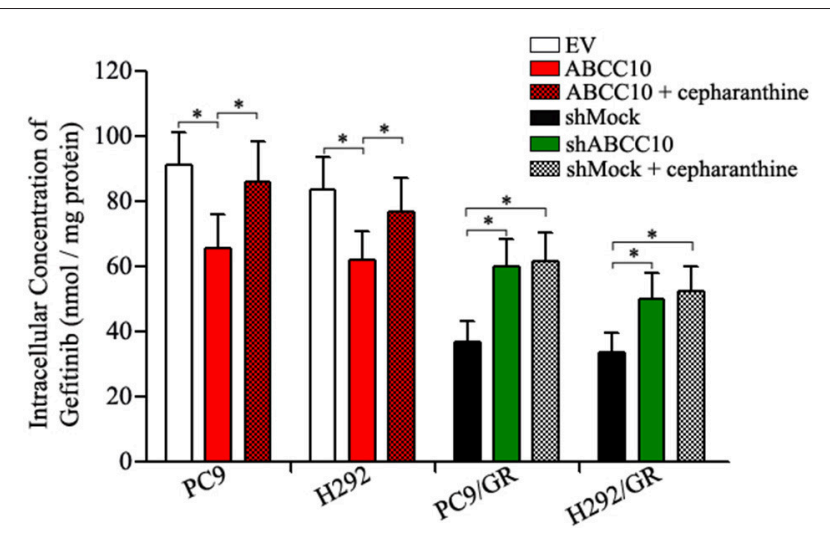

FIGURE 7 | Effect of ABCC10 on intracellular gefitinib concentration in gefitinib-sensitive and -resistant NSCLC cells. cells were incubated with 1 $\mu \mathrm{mol} / \mathrm{L}$ gefitinib with or without $2.5 \mu \mathrm{mol} / \mathrm{L}$ cepharanthine at $37^{\circ} \mathrm{C}$ for $4 \mathrm{~h}$, then the intracellular gefitinib concentration was determined by LC-MS/MS assay and expressed as nmol/mg of protein. ${ }^{*} P<0.05$ compared to the empty-vector-transfected cells (EV) or shMock-transfected cells (shMock).

inhibitors. However, despite a few early successes in preclinical studies, these inhibitors failed to improve the effectiveness of chemotherapy in clinical trials due to high toxicity and poor potency (Jaramillo et al., 2018; Mohammad et al., 2018; Robey et al., 2018). The toxicity of these inhibitors is mainly attributed to the inhibition of transporter expressed in normal tissues, and the cross reactivity with other $\mathrm{ABC}$ transporters or metabolism enzymes. For example, ABCB1 inhibitor valspodar was found to increase anticancer drug exposure through cytochrome P450 3A4 (CYP3A4) inhibition, while elacrida and tariquidar were found to inhibit both ABCB1 and ABCG2 (de Bruin et al., 1999; Bates et al., 2001; Kannan et al., 2011). Recent developments in tumortargeted drug delivery systems can be a promising approach to overcoming the side effects of these inhibitors (Binkhathlan and Lavasanifar, 2013; Callaghan et al., 2014). As for the insufficient potency of these inhibitors, one of the main causes may be the lack of full understanding of drug-transporter interactions in MDR. As we all know, one drug may be transported by multiple transporters. In MDR, more than one $\mathrm{ABC}$ transporter is likely to be involved in reducing drug accumulation, and the relative importance of these transporters is likely to vary among tumors (Tamaki et al., 2011). Since the expression of ABC transporters continue to be linked to poor outcome in clinic, more efforts should be devoted to investigate the functional aspects of $\mathrm{ABC}$ transporters in MDR. With these knowledge, even if the response to chemotherapy cannot be improved by $\mathrm{ABC}$ transporter inhibitor, we also can predict clinical response to certain drugs more accurately (Robey et al., 2018).

Recent research has suggested that some ABC transporters may alter the bioavailability of gefitinib at both the cellular and systemic levels, affecting the drug-target interaction and drug sensitivity (Beretta et al., 2017). But very little information is available till now. In the present study, we first established two NSCLC cell lines with acquired resistance to gefitinib, and aimed to identify more ABC transporters potentially involved in the mechanism of gefitinib resistance. In our developed gefitinib-resistant cells, either EGFR T790M mutation or amplification of the $M E T$ proto-oncogene was observed (data not shown). To the best of our knowledge, this is the first work that shows the differential expression of 48 protein coding $\mathrm{ABC}$ transporters between gefitinib-sensitive and -resistant NSCLC cells. The RNA-Seq data analysis revealed that most of these transporters did not exhibit significant changes in their expression levels, only the expression levels of $A B C G 2$ and $A B C C 10$ transcripts were significantly changed in both EGFR mutant (PC9) and wild-type (H292) NSCLC cell lines simultaneously. The significantly elevated ABCG2 expression in acquired gefitinib-resistant NSCLC cells has been shown previously both in vitro and in vivo (Usuda et al., 2007; Zhu et al., 2015), but the involvement of ABCC10 in the acquired resistance to EGFR-TKIs has not been reported so far. In this study, we found that both total and cellular membrane ABCC10 protein levels were significantly increased in acquired gefitinib-resistant NSCLC cells, and the increase of membrane ABCC10 level was more obvious than that of the total ABCC10 level. These results imply that some factors may influence the processes of biogenesis and traffic of ABCC10 in NSCLC cells with acquired resistance to gefitinib. To date, mechanisms that regulate ABCC10 expression are largely unknown. Two transcription factors, specificity protein 1 (Sp1) and E2 factor (E2F), as well as NIMArelated expressed kinase 2 (NEK2) have been shown to be involved in the ABCC10 expression regulation (Dabrowska and Sirotnak, 2004; Wu et al., 2017). In addation, some microRNAs, such as several members of let-7 family are referred to downregulate the ABCC10 level (Borel et al., 2012; Wu et al., 2016). Interestingly, previous studies have suggested that many microRNAs play important role in gefitinib resistance, and may also take part in the process of protein membrane trafficking (Sun et al., 2015; Zang et al., 2017). Therefore, regulatory factors, especially microRNAs, that are likely to influence the biogenesis and traffic of ABCC10 in NSCLC cells with acquired resistance to gefitinib warrant further investigation.

Next, we aimed to explore the role of ABCC10 in acquired resistance to gefitinib in NSCLC. We found that ABCC10 decreased the intracellular gefitinib concentration, prevented NSCLC cells from gefitinib-induced growth inhibition and apoptosis in vitro. And as expected, ABCC10 also enhanced tumor growth in gefitinib-treated NSCLC xenograft models. Therefore, we hypothesized that ABCC10 might decrease gefitinib sensitivity through pumping out gefitinib from NSCLC cells. To further address this issue, we performed in vitro transport study of gefitinib at submicromolar concentration in $\mathrm{ABCC} 10$-overexpressing LLC-PK1 cell monolayers. We found that ABCC10 could actively pump gefitinib out of cells, with an ER value of 7.8. According to a white paper published by International Transporter Consortium (ITC), a compound is considered a potential substrate of apically localized transporters if its transport ratio is $\geq 2$ (International Transporter Consortium et al., 2010). Moreover, cepharanthine, an ABCC10 inhibitor, almost completely inhibited gefitinib efflux from LLCABCC10 cells. Based on these results, we conclude that, for 
A

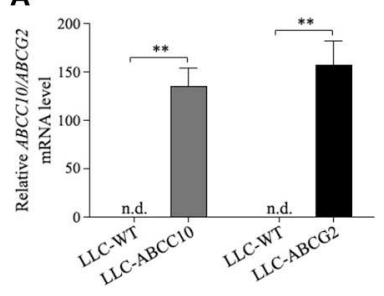

D

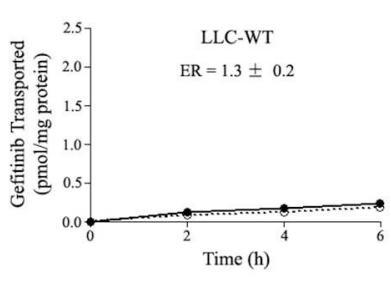

B

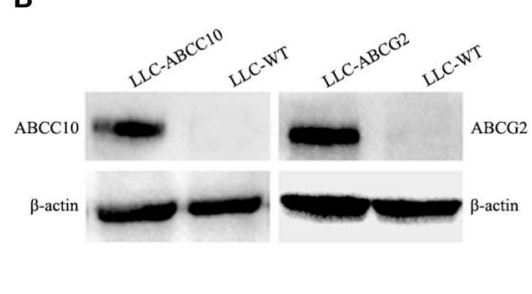

C
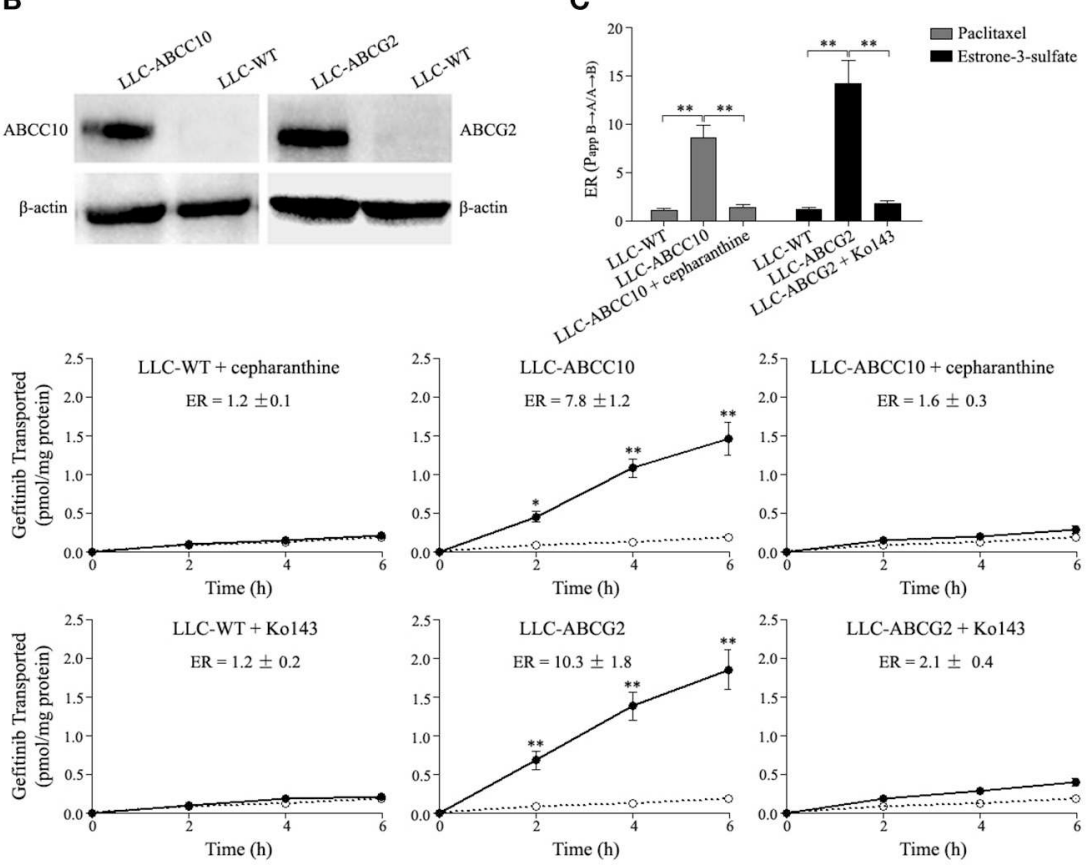
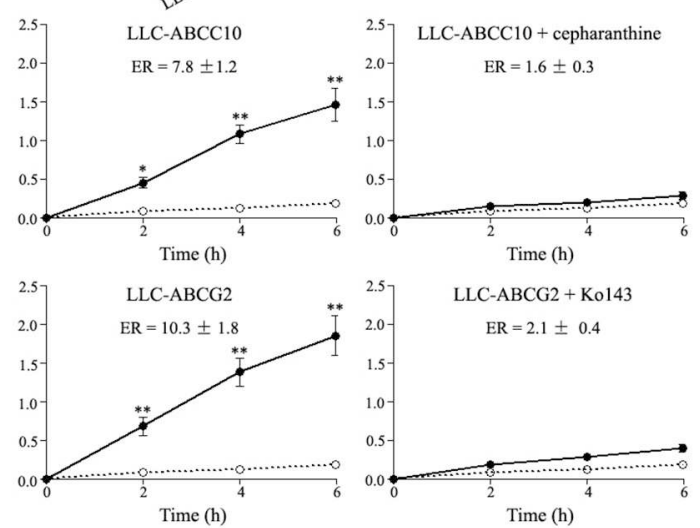

FIGURE 8 | ABCC10 and ABCG2-mediated transport of gefitinib in vitro. (A,B) Characterization of the LLC-PK1 cell line overexpression human ABCC10 or ABCG2. mRNA and protein levels of human ABCC10 or ABCG2 were detected in wildtype LLC-PK1 (LLC-WT) cells, as well as its subclones transduced with human ABCC10 (LLC-ABCC10) or ABCG2 (LLC-ABCG2). ${ }^{* *} P<0.01$ compared with LLC-WT cells. (C), Transepithelial transport of $100 \mathrm{nmol} / \mathrm{L}\left[{ }^{3} \mathrm{H}\right]$-paclitaxel and $10 \mathrm{nmol} / \mathrm{L}$ $\left[{ }^{3} \mathrm{H}\right]$-estrone-3-sulfate in LLC-WT, LLC-ABCC10, and LLC-ABCG2 cells. At $t=0 \mathrm{~h},\left[{ }^{3} \mathrm{H}\right]$-paclitaxel or $\left[{ }^{3} \mathrm{H}\right]$-estrone-3-sulfate was applied in one compartment (apical or basal). At $t=4 \mathrm{~h}$, the radioactivities were measured and the efflux ratios (ERs) were caluculated. ${ }^{\star *} P<0.01$ compared with LLC-WT cells. (D) Transepithelial transport of $100 \mathrm{nmol} / \mathrm{L}\left[{ }^{3} \mathrm{H}\right]$-gefitinib was assessed in LLC-PK1 cells. At $t=0 \mathrm{~h},\left[{ }^{3} \mathrm{H}\right]$-gefitinib was applied in one compartment (apical or basal), and the radioactivities at $t=2,4$, and $6 \mathrm{~h}$ were measured and plotted over time. Closed circles, translocation from the basal to the apical compartment; open circles, translocation from the apical to the basal compartment. ${ }^{\star} P<0.05$, ${ }^{\star \star} P<0.01$ compared to the translocation from the apical to the basal compartment.

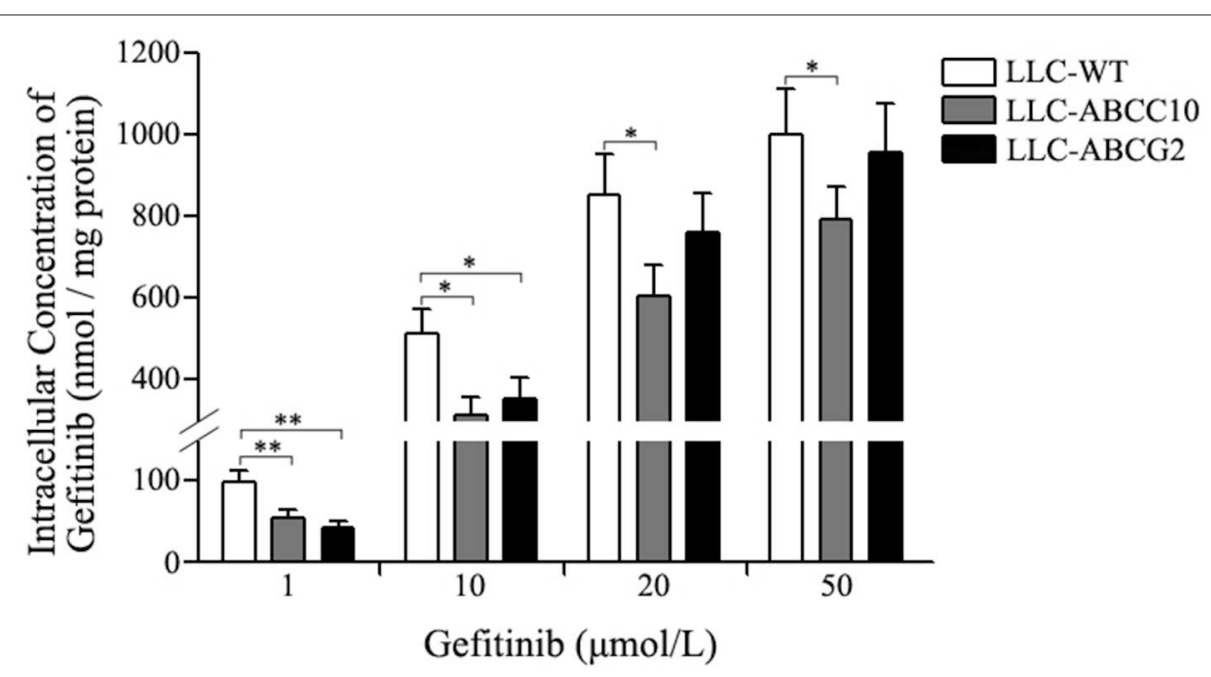

FIGURE 9 | Intracellular gefitinib concentration in LLC-PK1 cells either wildtype (LLC-WT) or transduced with human ABCC10 (LLC-ABCC10) or ABCG2 (LLC-ABCG2) CDNA. cells were incubated with 1, 10, 20, and $50 \mu \mathrm{mol} / \mathrm{L}$ gefitinib at $37^{\circ} \mathrm{C}$ for $4 \mathrm{~h}$, then the intracellular gefitinib concentration was determined by LC-MS/MS assay and expressed as nmol/mg of protein. ${ }^{\star} P<0.05,{ }^{\star *} P<0.01$ compared to the LLC-WT cells.

the first time, ABCC10 actively mediates the transport of gefitinib, and is involved in acquired resistance to gefitinib in NSCLC cells.
To our knowledge only three members of $A B C$ transporter subfamily (i.e., $\mathrm{ABCG} 2, \mathrm{ABCB} 1$, and $\mathrm{ABCC} 1$ ) have been examined with respect to their gefitinib efflux activities so far. 

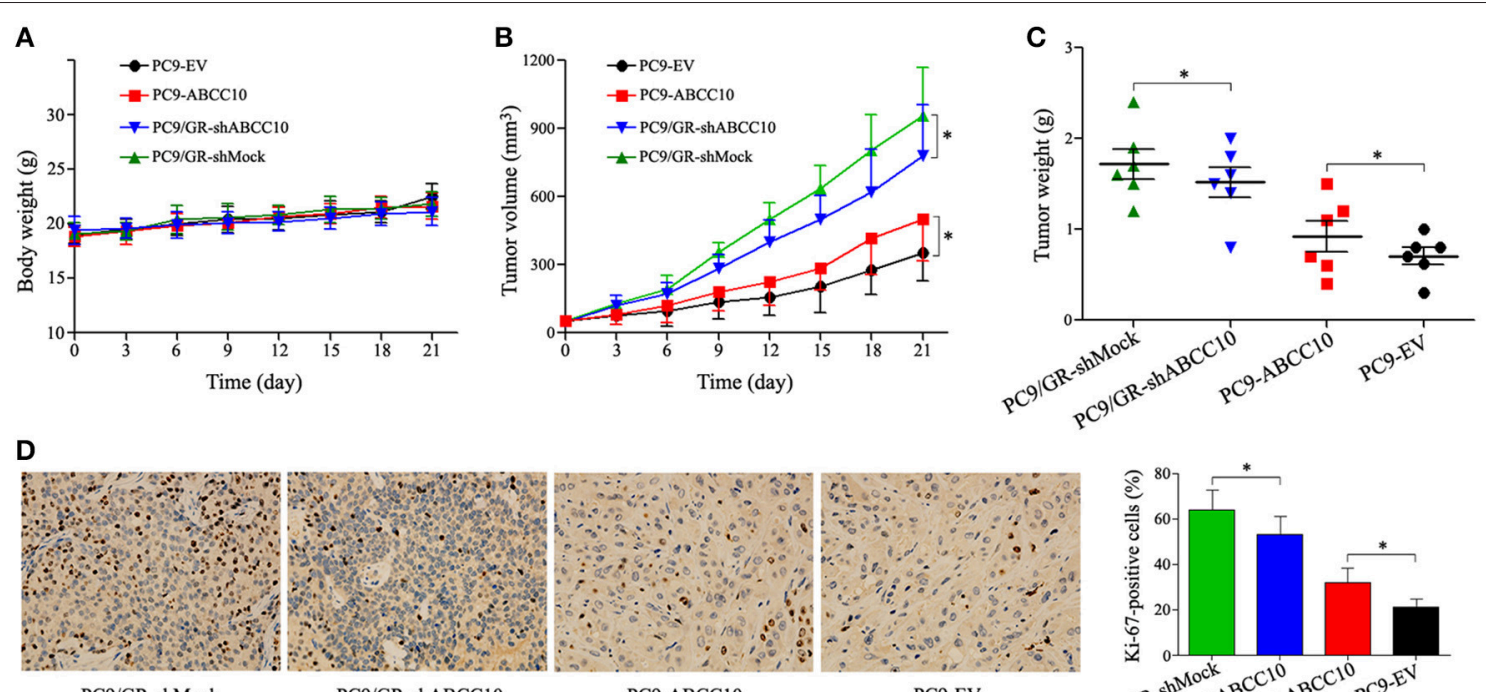

PC9/GR-shMock
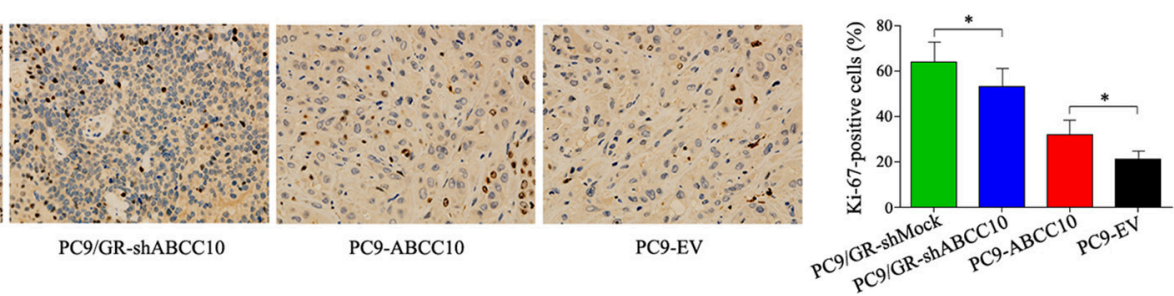

FIGURE 10 | Effect of ABCC10 on gefitinib sensitivity in PC9 xenograft mice model. Nude mice were implanted subcutaneously with the indicated cell lines and were treated with gefitinib (30 mg/kg/day) for 3 weeks ( $n=6$ per group). (A) Average body weight curves of Balb/c-nude mice. (B) TV was measured as indicated in Materials and methods. (C) Tumor weights were analyzed at the end of experiment. (D) Proliferation was detected using anti-Ki-67 antibody. Graphs show the percentage of Ki-67-positive cells in each group. Photos of $\mathrm{IHC}$ staining are representative of at least 10 similar observations $(\times 400)$. ${ }^{\star} P<0.05$ compared to the PC9/GR-shMock or PC9-EV group.

Unfortunately, previous study has shown that gefitinib exhibits little or no affinity for ABCB1 and ABCC1 (Ozvegy-Laczka et al., 2004). Considering no changes in the levels of these two transporters were observed in our gefitinib-resistant NSCLC cells, we come to a conclusion that $\mathrm{ABCB} 1$ and $\mathrm{ABCC} 1$ are unlikely to play a role in the development of acquired resistance to gefitinib in NSCLC. Although it is well established that gefitinib is able to interact with ABCG2, there is, however, controversy over whether gefitinib is a substrate or inhibitor of ABCG2. Some studies have shown that gefitinib is actively extruded by ABCG2, while others indicate that gefitinib is an inhibitor but not a substrate of ABCG2. It is now generally believed that gefitinib can be efflux by ABCG2 at submicromolar concentrations, whereas at higher concentrations it is likely to act as an inhibitor (Ozvegy-Laczka et al., 2004; Leggas et al., 2006; Azzariti et al., 2010; Hegedüs et al., 2012; Beretta et al., 2017). In the present study, we also observed the ABCG2-mediated transport of gefitinib at submicromolar concentration, the unbound plasma level of gefitinib. We found an active efflux of gefitinib by ABCG2, with an ER value of 10.3. This indicates that at submicromolar concentration, the ABCG2-mediated gefitinib transport activity is higher than that of ABCC10. Consistently, we found a lower intracellular gefitinib accumulation in the LLC-ABCG2 cells than in the LLC-ABCC10 cells after 1 $\mu \mathrm{mol} / \mathrm{L}$ gefitinib incubation. However, the intracellular gefitinib accumulation in the LLC-ABCG2 cells tend to be higher than in the LLC-ABCC10 cells after $10 \mu \mathrm{mol} / \mathrm{L}$ gefitinib incubation. And at more higher gefitinib concentrations, no significant decrease in intracellular gefitinib concentration could be observed in the LLC-ABCG2 cells compared with LLC-WT cells, but still could be detected in the LLC-ABCC10 cells. These results indicate that ABCG2-mediated gefitinib efflux activity will be decreased with the increase of gefitinib concentration, but $\mathrm{ABCC} 10$ can activity extrude gefitinib even at concentration as high as $50 \mu \mathrm{mol} / \mathrm{L}$. Considering the gefitinib concentration in NSCLC tumor tissues is more than 40 -fold higher than plasma levels, we speculate that $\mathrm{ABCC} 10$ may play a more important role than ABCG2 in acquired resistance to gefitinib in vivo (McKillop et al., 2005; Haura et al., 2010).

In summary, our results show that $\mathrm{ABCC} 10$ is overexpressed in NSCLC cells with acquired resistance to gefitinib, independent of EGFR mutation status. As a substrate, gefitinib can be actively transported by $\mathrm{ABCC} 10$, even at concentration as high as $50 \mu \mathrm{mol} / \mathrm{L}$. ABCC10-mediated gefitinib efflux leads to a decrease in the intracellular accumulation, as well as antitumor efficacy of gefitinib in NSCLC in vitro and in vivo. This study shed more light on the factors that influence acquired resistance to gefitinib, and proposes that $\mathrm{ABCC} 10$ can be as a novel predictive marker, as well as a potential therapeutic target for gefitinib acquired resistance in NSCLC.

\section{AUTHOR CONTRIBUTIONS}

HZha, YH, and JS performed the experiments and analyzed the data. HZha and YD interpreted the data and drafted the manuscript. LW and HZho designed the study, supervised the work and wrote the final version of the manuscript. All authors agree to be accountable for the content of the work. 


\section{FUNDING}

This work was supported by the National Scientific Foundation of China (No. 81473284, 8157 1457).

\section{REFERENCES}

Azzariti, A., Porcelli, L., Simone, G. M., Quatrale, A. E., Colabufo, N. A., Berardi, F., et al. (2010). Tyrosine kinase inhibitors and multidrug resistance proteins: interactions and biological consequences. Cancer Chemother. Pharmacol. 65, 335-346. doi: 10.1007/s00280-009-1039-0

Bates, S., Kang, M., Meadows, B., Bakke, S., Choyke, P., Merino, M., et al. (2001). A phase I study of infusional vinblastine in combination with the P-glycoprotein antagonist PSC 833 (valspodar). Cancer 92, 1577-1590. doi: 10.1002/1097-0142(20010915)92:6\&lt;1577::AIDCNCR1484\&gt;3.0.CO;2-H

Beretta, G. L., Cassinelli, G., Pennati, M., Zuco, V., and Gatti, L. (2017). Overcoming $\mathrm{ABC}$ transporter-mediated multidrug resistance: the dual role of tyrosine kinase inhibitors as multitargeting agents. Eur. J. Med. Chem. 142, 271-289. doi: 10.1016/j.ejmech.2017.07.062

Binkhathlan, Z., and Lavasanifar, A. (2013). P-glycoprotein inhibition as a therapeutic approach for overcoming multidrug resistance in cancer: current status and future perspectives. Curr. Cancer Drug Targets. 13, 326-346. doi: 10.2174/15680096113139990076

Borel, F., Han, R., Visser, A., Petry, H., van Deventer, S. J., Jansen, P. L., et al. (2012). Adenosine triphosphate-binding cassette transporter genes upregulation in untreated hepatocellular carcinoma is mediated by cellular microRNAs. Hepatology 55, 821-832. doi: 10.1002/hep.24682

Callaghan, R., Luk, F., and Bebawy, M. (2014). Inhibition of the multidrug resistance P-glycoprotein: time for a change of strategy? Drug Metab. Dispos. 42, 623-631. doi: 10.1124/dmd.113.056176

Chen, Y. J., Huang, W. C., Wei, Y. L., Hsu, S. C., Yuan, P., Lin, H. Y., et al. (2011). Elevated BCRP/ABCG2 expression confers acquired resistance to gefitinib in wild-type EGFR-expressing cells. PLoS ONE 6:e21428. doi: 10.1371/journal.pone.0021428

Dabrowska, M., and Sirotnak, F. M. (2004). Regulation of transcription of the human MRP7 gene. Characteristics of the basal promoter and identification of tumor-derived transcripts encoding additional 5' end heterogeneity. Gene 341, 129-139. doi: 10.1016/j.gene.2004.06.022

Dabrowska, M., and Sirotnak, F. M. (2017). E2F site in the essential promoter region does not confer $S$ phase-specific transcription of the ABCC10 gene in human prostate cancer cells. Acta Biochim. Pol. 64, 371-374. doi: 10.18388/abp.2017_1521

de Bruin, M., Miyake, K., Litman, T., Robey, R., and Bates, S. E. (1999). Reversal of resistance by GF120918 in cell lines expressing the ABC half-transporter, MXR. Cancer Lett. 146, 117-126. doi: 10.1016/S0304-3835(99)00182-2

Douillard, J. Y., Ostoros, G., Cobo, M., Ciuleanu, T., McCormack, R., Webster, A., et al. (2014). First-line gefitinib in Caucasian EGFR mutation-positive NSCLC patients: a phase-IV, open-label,single-arm study. Br. J. Cancer 110, 55-62. doi: 10.1038/bjc.2013.721

Ennis, B. W., Lippman, M. E., and Dickson, R. B. (1991). The EGF receptor system as a target for antitumor therapy. Cancer Invest. 9, 553-562. doi: $10.3109 / 07357909109018953$

Gandara, D. R., Li, T., Lara, P. N., Kelly, K., Riess, J. W., Redman, M. W., et al. (2014). Acquired resistance to targeted therapies against oncogenedriven non-small-cell lung cancer: approach to subtyping progressive disease and clinical implications. Clin. Lung Cancer 15, 1-6. doi: 10.1016/j.cllc.2013. 10.001

Gridelli, C., De Marinis, F., Di Maio, M., Cortinovis, D., Cappuzzo, F., and Mok, T. (2011). Gefitinib as first-line treatment for patients with advanced non-small-cell lung cancer with activating epidermal growth factor receptor mutation: implications for clinical practice and open issues. Lung Cancer 72, 3-8. doi: 10.1016/j.lungcan

\section{SUPPLEMENTARY MATERIAL}

The Supplementary Material for this article can be found online at: https://www.frontiersin.org/articles/10.3389/fphar. 2018.01312/full\#supplementary-material
Haura, E. B., Sommers, E., Song, L., Chiappori, A., and Becker, A. (2010). A pilot study of preoperative gefitinib for early-stage lung cancer to assess intratumor drug concentration and pathways mediating primary resistance. J. Thorac. Oncol. 5, 1806-1814. doi: 10.1097/JTO.0b013e3181f38f70

Hegedüs, C., Truta-Feles, K., Antalffy, G., Várady, G., Német, K., Ozvegy-Laczka, C., et al. (2012). Interaction of the EGFR inhibitors gefitinib, vandetanib, pelitinib and neratinib with the ABCG2 multidrug transporter: implications for the emergence and reversal of cancer drug resistance. Biochem. Pharmacol. 84, 260-267. doi: 10.1016/j.bcp.2012.04.010

Hopper-Borge, E., Chen, Z. S., Shchaveleva, I., Belinsky, M. G., and Kruh, G. D. (2004). Analysis of the drug resistance profile of multidrug resistance protein 7 (ABCC10): resistance to docetaxel. Cancer Res. 64, 4927-4930. doi: 10.1158/0008-5472.CAN-03-3111

International Transporter Consortium, Giacomini, K. M., Huang, S. M., Tweedie, D. J., Benet, L. Z., Brouwer, K. L., et al. (2010). Membrane transporters in drug development. Nat. Rev. Drug Discov. 9, 215-236. doi: 10.1038/nrd3028

Jaramillo, A. C., Saig, F. A., Cloos, J., Jansen, G., and Peters, G. J. (2018). How to overcome ATP-binding cassette drug efflux transporter-mediated drug resistance? Cancer Drug Resist. 1, 6-29. doi: 10.20517/cdr.2018.02

Jutten, B., and Rouschop, K. M. (2014). EGFR signaling and autophagy dependence for growth, survival, and therapy resistance. Cell Cycle 13, 42-51. doi: $10.4161 /$ cc. 27518

Kannan, P., Telu, S., Shukla, S., Ambudkar, S. V., Pike, V. W., Halldin, C., et al. (2011). The "specific" P-glycoprotein inhibitor Tariquidar is also a substrate and an inhibitor for breast cancer resistance protein (BCRP/ABCG2). ACS Chem. Neurosci. 2, 82-89. doi: 10.1021/cn100078a

Kuang, Y. H., Shen, T., Chen, X., Sodani, K., Hopper-Borge, E., Tiwari, A. K., et al. (2010). Lapatinib and erlotinib are potent reversal agents for MRP7 (ABCC10)-mediated multidrug resistance. Biochem. Pharmacol. 79, 154-161. doi: 10.1016/j.bcp.2009.08.021

Leggas, M., Panetta, J. C., Zhuang, Y., Schuetz, J. D., Johnston, B., Bai, F., et al. (2006). Gefitinib modulates the function of multiple ATPbinding cassette transporters in vivo. Cancer Res. 66, 4802-4807. doi: 10.1158/0008-5472.CAN-05-2915

Livak, K. J., and Schmittgen, T. D. (2001). Analysis of relative gene expression data using real-time quantitative PCR and the $2_{\mathrm{T}}^{-\Delta \Delta C}$ Method. Methods 25, 402-408. doi: 10.1006/meth.2001.1262

McKillop, D., Partridge, E. A., Kemp, J. V., Spence, M. P., Kendrew, J., Barnett, S., et al. (2005). Tumor penetration of gefitinib (Iressa), an epidermal growth factor receptor tyrosine kinase inhibitor. Mol. Cancer Ther. 4, 641-649. doi: 10.1158/1535-7163.MCT-04-0329

Mohammad, I. S., He, W., and Yin, L. (2018). Understanding of human ATP binding cassette superfamily and novel multidrug resistance modulators to overcome MDR. Biomed. Pharmacother. 100, 335-348. doi: 10.1016/j.biopha.2018.02.038

Morgillo, F., Della Corte, C. M., Fasano, M., and Ciardiello, F. (2016). Mechanisms of resistance to EGFR-targeted drugs: lung cancer. ESMO Open 1:e000060. doi: 10.1136/esmoopen-2016-000060.

Nakayama, A., Matsuo, H., Takada, T., Ichida, K., Nakamura, T., Ikebuchi, Y., et al. (2011). ABCG2 is a high-capacity urate transporter and its genetic impairment increases serum uric acid levels in humans. Nucleosides Nucleotides Nucleic Acids. 30, 1091-1097. doi: 10.1080/15257770.2011.633953

Ozvegy-Laczka, C., Hegedus, T., Várady, G., Ujhelly, O., Schuetz, J. D., Váradi, A., et al. (2004). High-affinity interaction of tyrosine kinase inhibitors with the ABCG2 multidrug transporter. Mol. Pharmacol. 65, 1485-1495. doi: 10.1124/mol.65.6.1485

Revalde, J. L., Li, Y., Hawkins, B. C., Rosengren, R. J., and Paxton, J. W. (2015). Heterocyclic cyclohexanone monocarbonyl analogs of curcumin can inhibit the 
activity of ATP-binding cassette transporters in cancer multidrug resistance. Biochem. Pharmacol. 93, 305-317. doi: 10.1016/j.bcp.2014.12.012

Ridge, C. A., McErlean, A. M., and Ginsberg, M. S. (2013). Epidemiology of lung cancer. Semin. Intervent. Radiol. 30, 93-98. doi: 10.1055/s-0033-1342949.

Robey, R. W., Pluchino, K. M., Hall, M. D., Fojo, A. T., Bates, S. E., and Gottesman, M. M. (2018). Revisiting the role of ABC transporters in multidrug-resistant cancer. Nat. Rev. Cancer 18, 452-464. doi: 10.1038/s41568-018-0005-8

Salomon, D. S., Brandt, R., Ciardiello, F., and Normanno, N. (1995). Epidermal growth factor-related peptides and their receptors in human malignancies. Crit. Rev. Oncol. Hematol. 19, 183-232. doi: 10.1016/1040-8428(94)00144-I

Schinkel, A. H., and Jonker, J. W. (2003). Mammalian drug efflux transporters of the ATP binding cassette (ABC) family: an overview. Adv. Drug. Deliv. Rev. 55, 3-29. doi: 10.1016/S0169-409X(02)00169-2

Shaik, N., Giri, N., Pan, G., and Elmquist, W. F. (2007). P-glycoproteinmediated active efflux of the anti-HIV1 nucleoside abacavir limits cellular accumulation and brain distribution. Drug Metab. Dispos. 35, 2076-2085. doi: 10.1124/dmd.107.017723.

Shepherd, F. A. (2016). Should EGFR tyrosine kinase inhibitors be used in nonsmall cell lung cancer in the absence of EGFR mutations? Yes, there is a role for EGFR TKIs in these patients. Clin. Adv. Hematol. Oncol. 14, 41-43.

Sun, L. H., Yan, M. L., Hu, X. L., Peng, L. W., Che, H., Bao, Y. N., et al. (2015). MicroRNA-9 induces defective trafficking of Nav1.1 and Nav1.2 by targeting Nav $\beta 2$ protein coding region in rat with chronic brain hypoperfusion. Mol. Neurodegener. 10:36. doi: 10.1186/s13024-015-0032-9

Tabata, K., Tanaka, T., Hayashi, T., Hori, T., Nunomura, S., Yonezawa, S., et al. (2014). Ki-67 is a strong prognostic marker of non-small cell lung cancer when tissue heterogeneity is considered. BMC Clin. Pathol. 14:23. doi: 10.1186/1472-6890-14-23

Tamaki, A., Ierano, C., Szakacs, G., Robey, R. W., and Bates, S. E. (2011). The controversial role of $\mathrm{ABC}$ transporters in clinical oncology. Essays Biochem. 50, 209-232. doi: 10.1042/bse0500209

Tas, F., Ciftci, R., Kilic, L., and Karabulut, S. (2013). Age is a prognostic factor affecting survival in lung cancer patients. Oncol. Lett. 6, 1507-1513. doi: 10.3892/ol.2013.1566

Usuda, J., Ohira, T., Suga, Y., Oikawa, T., Ichinose, S., Inoue, T., et al. (2007). Breast cancer resistance protein (BCRP) affected acquired resistance to gefitinib in a "never-smoked" female patient with advanced non-small cell lung cancer. Lung Cancer 58, 296-299. doi: 10.1016/j.lungcan.2007.05.019

Wu, K., Yang, Y., Zhao, J., and Zhao, S. (2016). BAG3-mediated miRNA let-7g and let-7i inhibit proliferation and enhance apoptosis of human esophageal carcinoma cells by targeting the drug transporter ABCC10. Cancer Lett. 371, 125-133. doi: 10.1016/j.canlet.2015.11.031

Wu, S. M., Lin, S. L., Lee, K. Y., Chuang, H. C., Feng, P. H., Cheng, W. L., et al. (2017). Hepatoma cell functions modulated by NEK2 are associated with liver cancer progression. Int. J. Cancer 140, 1581-1596. doi: 10.1002/ijc.30559

Zang, H., Wang, W., and Fan, S. (2017). The role of microRNAs in resistance to targeted treatments of non-small cell lung cancer. Cancer Chemother. Pharmacol. 79, 227-231. doi: 10.1007/s00280-0163130-7

Zhou, F., and Zhou, C. C. (2015). Targeted therapies for patients with advanced NSCLC harboring wild-type EGFR: what's new and what's enough. Chin. J. Cancer 34, 310-319. doi: 10.1186/s40880-015-0036-4

Zhou, Y., Hopper-Borge, E., Shen, T., Huang, X. C., Shi, Z., Kuang, Y. H., et al. (2009). Cepharanthine is a potent reversal agent for MRP7(ABCC10)-mediated multidrug resistance. Biochem. Pharmacol. 77, 993-1001. doi: 10.1016/j.bcp.2008.12.005

Zhu, Y., He, W., Gao, X., Li, B., Mei, C., Xu, R., et al. (2015). Resveratrol overcomes gefitinib resistance by increasing the intracellular gefitinib concentration and triggering apoptosis, autophagy and senescence in PC9/G NSCLC cells. Sci. Rep. 5:17730. doi: 10.1038/srep17730

Conflict of Interest Statement: The authors declare that the research was conducted in the absence of any commercial or financial relationships that could be construed as a potential conflict of interest.

Copyright $\odot 2018$ Zhao, Huang, Shi, Dai, Wu and Zhou. This is an open-access article distributed under the terms of the Creative Commons Attribution License (CC $B Y)$. The use, distribution or reproduction in other forums is permitted, provided the original author(s) and the copyright owner(s) are credited and that the original publication in this journal is cited, in accordance with accepted academic practice. No use, distribution or reproduction is permitted which does not comply with these terms. 